\title{
O livro didático: alguns temas de pesquisa
}

\section{Kazumi Munakata*}

\begin{abstract}
Resumo:
As pesquisas sobre o livro didático obtiveram grande crescimento nos anos 1990 e 2000, incorporando aportes da história do currículo e das disciplinas escolares, da história cultural e da história do livro e da leitura. Organizaram-se centros e grupos de pesquisa; promoveram-se projetos e eventos sobre o tema, no âmbito brasileiro e internacional. Este artigo descreve, resumidamente, a constituição desse campo de pesquisa com a formulação de referenciais teóricos e metodológicos, assim como enumera algumas pesquisas recentemente realizadas que exemplificam a atual diversificação temática, que tem permitido examinar o livro didático como elemento fundamental das políticas públicas de educação, das práticas didáticas e da constituição e transmissão dos saberes e da cultura escolar.
\end{abstract}

\section{Palavras-chave:}

livro didático; politicas educacionais; cultura escolar; disciplinas escolares; mercado editorial.

\footnotetext{
Professor do Programa de Estudos Pós-Graduados em Educação: História, Política, Sociedade, da Pontifícia Universidade Católica de São Paulo; integrou o Projeto Temático "Educação e Memória: Organização de Acervos de Livros Didáticos", coordenado por Circe Bittencourt e financiado pela FAPESP e participa do projeto Manes (Manuales Escolares), da Universidad Nacional de Educacación a Distancia (Espanha) e Redes de Estudios en Lectura y Escritura (Argentina).
} 


\title{
The textbook: some research themes
}

\section{Kazumi Munakata}

\begin{abstract}
:
Researches on the textbook presented fast growth in the 1990's and 2000 's, incorporating contributions from the history of curriculum and school disciplines, cultural history, and from the history of books and reading. Research centers and groups were organized; national and international projects and events on the theme were promoted. This article describes, in a brief way, the constitution of this field of research with the formulation of theoretical and methodological frameworks, and also lists some researches recently carried out that exemplify the current thematic diversification, which has allowed to examine the textbook as a fundamental part of public policies in education, didactic practices, and the constitution and dissemination of school knowledge and culture.
\end{abstract}

\section{Keywords:}

textbook; educational policies; school culture; school discip; publishing market. 


\section{Aos meus orientandos e colegas de pesquisa sobre livro didático}

Em 1993, quando Circe Bittencourt (1993) defendeu a sua tese sobre livro didático, os trabalhos acadêmicos brasileiros sobre o tema, publicados nos anos 1970 e 1980, não passavam de quase 50 títulos $^{1}$. Destes, uma parcela significativa destinava-se a condenar a ideologia (burguesa) subjacente aos livros utilizados na escola (MUNAKATA, 1998). Daquela época em diante, porém, o número das pesquisas sobre essa modalidade de material escolar não tem parado de crescer: 22 títulos entre 1993 e 1995; 29 em 1996; 26 em 1997; 63 em 1998; 79 em 1999; e 46 em 2000. O expressivo número referente a 1999 pode ser tributado à realização, naquele ano, na Universidade do Minho (Portugal), do I Encontro Internacional sobre Manuais Escolares: Manuais Escolares - Estatuto, Funções, História, com a participação de vários pesquisadores brasileiros (CASTRO et al., 1999). Como esse, começaram a se organizar eventos específicos sobre o tema, caso do Simpósio Internacional "Livro Didático: Educação e História", realizado na Universidade de São Paulo, em 2007²; sessões especiais sobre o tema passaram a ser abrigadas nos eventos das grandes áreas. Centros, núcleos e projetos de pesquisa sobre o tema também foram se constituindo nos programas de pós-graduação das diferentes áreas (educação, letras, história, matemática etc.). O resultado disso é a surpreendente cifra de cerca de 800 trabalhos sobre o livro didático produzidos de 2001 a $2011^{3}$.

1 Esses dados quantitativos e os mencionados a seguir foram extraídos de um banco de dados de bibliografia sobre livros didáticos, organizado pelo autor como atividade do Projeto Temático "Educação e memória: organização de acervos de livros didáticos", coordenado por Circe Bittencourt e financiado pela FAPESP. Cabe observar que não se pretendeu nesse banco de dados a coleta da totalidade das referências bibliográficas sobre o tema, o que não impede que suas informações sejam utilizadas como parâmetros. Relacionaram-se não apenas os trabalhos que abordam explicitamente o livro didático, como também aqueles que, embora não o focalizem diretamente, reservam um bom espaço para o tema.

2 Neste evento, que contou com a participação de vários especialistas nacionais e internacionais, inscreveram-se 176 comunicações (SIMPÓSIO..., 2007).

3 A multiplicação dos eventos, periódicos acadêmicos e projetos que focalizam o livro didático tornou ainda mais difícil registrar a totalidade das ocorrências, o que significa que certamente se produziu no período um número bem maior que 800 trabalhos. 
Essa expansão de pesquisas sobre o livro didático não foi apenas um fenômeno brasileiro, mas tendência internacional. Como se vê no Quadro 1, em várias partes do mundo foram se constituindo centros de pesquisa sobre o tema, nos anos 1980, 1990 e 2000, à exceção de Georg Eckert Institute for International Textbook Research, criado em 1975, praticamente uma instituição originária.

Quadro 1. Centros de Pesquisa sobre livros didáticos no mundo.

\begin{tabular}{|l|l|c|l|}
\hline \multicolumn{1}{|c|}{ Nome } & \multicolumn{1}{|c|}{ País } & Ano & \multicolumn{1}{c|}{ Site } \\
\hline $\begin{array}{l}\text { Georg Eckert Institute for } \\
\text { International Textbook }\end{array}$ & Alemanha & 1975 & $\begin{array}{l}\text { http://www.gei.de/nc/en/ } \\
\text { georg-eckert-institute- } \\
\text { for-international- } \\
\text { textbook-research.html }\end{array}$ \\
\hline $\begin{array}{l}\text { Programme de Recherches } \\
\text { Emmanuelle }\end{array}$ & França & 1980 & $\begin{array}{l}\text { http://www.inrp.fr/she/ } \\
\text { emmanuelle.htm }\end{array}$ \\
\hline The Textbook Colloquium & $\begin{array}{l}\text { Grã- } \\
\text { Bretanha }\end{array}$ & 1988 & $\begin{array}{l}\text { http://faculty.ed.uiuc. } \\
\text { edu/westbury/paradigm/ } \\
\text { colloq2.html* } \\
\text { http://www.open.ac.uk/ } \\
\text { Arts/TEXTCOLL/ } \\
\text { http://faculty.ed.uiuc. } \\
\text { edu/westbury/paradigm/ }\end{array}$ \\
\hline $\begin{array}{l}\text { International Association for } \\
\text { Research on Textbooks and } \\
\text { Educational Media (IARTEM) }\end{array}$ & Noruega & 1991 & $\begin{array}{l}\text { http://www.iartem.no/ } \\
\text { index.html }\end{array}$ \\
\hline $\begin{array}{l}\text { Centro de Investigación } \\
\text { MANES (Manuales Escolares) }\end{array}$ & Espanha & 1992 & $\begin{array}{l}\text { http://www.uned. } \\
\text { es/manesvirtual/ } \\
\text { ProyectoManes/ }\end{array}$ \\
\hline $\begin{array}{l}\text { Les Manuels Scolaires } \\
\text { Québécois }\end{array}$ & Canadá & $1993 * *$ & $\begin{array}{l}\text { http://www.bibl.ulaval. } \\
\text { ca/ress/manscol }\end{array}$ \\
\hline $\begin{array}{l}\text { Centro Internacional de la } \\
\text { Cultura Escolar (CEINCE) }\end{array}$ & Espanha & 2006 & $\begin{array}{l}\text { http://www.ceince.eu/ } \\
\text { main.php?id=1 }\end{array}$ \\
\hline $\begin{array}{l}\text { Redes de Estudios en Lectura } \\
\text { y Escritura (RELEE) }\end{array}$ & Argentina & 2007 & $\begin{array}{l}\text { http://hum.unne.edu. } \\
\text { ar/investigacion/educa/ } \\
\text { web_relee/inicio.htm }\end{array}$ \\
\hline
\end{tabular}

*Inexplicavelmente, há três sites dessa entidade; o último refere-se à revista Paradigm.

**Data presumível. 
No Brasil, o trabalho de Circe Bittencourt (1993) representou o impulso inicial da vasta produção das décadas seguintes, na medida em que apresentou um conjunto de temas e abordagens que o objeto comportava para além da denúncia da ideologia. A tese, publicada tardiamente como livro em 2008 (BITTENCOURT, 2008), tratava da questão do livro didático como política pública educacional, mas também enveredava em questões como a produção editorial desse objeto para o mercado, a sua inserção na escola como dispositivo constitutivo do saber e da cultura escolar, a sua importância como suporte de disciplinas escolares (em particular, de história ensinada) e os usos e as práticas que incidem sobre esse material.

Essa renovação temática tinha como referência autores como Chervel, Goodson (1995), Choppin e Chartier, que efetivavam, desde os anos 1970, discussões sobre o currículo, as disciplinas escolares, a cultura escolar, a história cultural e a história do livro e da leitura. Este último campo formula um pressuposto que se revelaria fundamental para pesquisas sobre o livro e o livro didático: a irredutibilidade entre o texto e o livro. A citação de Chartier (1990, p. 126-127) é por demais conhecida:

Contra a representação [...] do texto ideal, abstrato, estável porque desligado de qualquer materialidade, é necessário recordar vigorosamente que não existe nenhum texto fora do suporte que o dá a ler, que não há compreensão de um escrito, qualquer que ele seja, que não dependa das formas através das quais ele chega ao seu leitor. Daí a necessária separação de dois tipos de dispositivos: os que decorrem do estabelecimento do texto, das estratégias de escrita, das intenções do "autor"; e os dispositivos que resultam da passagem a livro ou a impresso, produzidos pela decisão editorial ou pelo trabalho da oficina, tendo em vista leitores ou leituras que podem não estar de modo nenhum em conformidade com os pretendidos pelo autor. Esta distância, que constitui o espaço no qual se constrói o sentido, foi muitas vezes esquecida pelas abordagens clássicas que pensam a obra em si mesma, como um texto puro cujas formas tipográficas não têm importância, e também pela teoria da recepção que postula uma relação direta, imediata, entre o "texto" e o leitor, entre os "sinais textuais" manejados pelo autor e o "horizonte de expectativa" daqueles a quem se dirige.

Recusou-se, portanto, um certo idealismo ingênuo que abordava o livro (didático) como um simples conjunto de ideias e valores que deveriam ser condenados (ou aprovados) segundo uma certa ortodoxia. Entre a enunciação das ideias e dos valores e a sua recepção, há, sempre, a mediação 
da materialidade do objeto-livro, que deve ser levada em conta. O livro é papel e tinta formando a mancha (a área impressa de uma página); o que ali se imprime passa por edição e copidesque (que muitas vezes introduzem alterações no texto original), revisão e preparação de texto, que, então, é organizado em páginas (paginação), de acordo com um projeto editorial; as páginas formam cadernos de um certo formato, que são colados ou costurados e encadernados, recebendo procedimentos de acabamento editorial e gráfico; para, finalmente, ser distribuído, e (eventualmente) lido.

Alguns pesquisadores, pretendendo apreender a "materialidade", passaram a medir, régua em punho, o tamanho das páginas. Mas materialidade não é apenas isso: além do tamanho da página, há várias medidas tipográficas - paica, cícero, corpo etc. - que demarcam outros aspectos materiais do livro (ARAÚJO, 1986; RIBEIRO, 2003). Apreender a materialidade é, antes, conhecer o processo de produção, circulação e consumo de livros, no interior do qual seus elementos, por exemplo, o tamanho da página, adquire inteligibilidade.

A noção de materialidade, em suma, remete à materialidade das relações sociais em que os livros (inclusive didáticos) estão implicados. Na esfera da produção, diversas modalidades de trabalho concorrem para que o livro venha à luz. Esses trabalhos são geralmente executados por diversos trabalhadores em suas especializações (editores, revisores, paginadores, artes-finalistas, impressores, encadernadores etc.), embora não seja impossível que todos esses trabalhos especializados sejam realizados por um só trabalhador ou por um punhado deles (MUNAKATA, 1997). A circulação, em se tratando de livro didático no Brasil, é uma operação complexa, exatamente pela materialidade desse objeto: imagine-se, por exemplo, a logística envolvida para que os 160 milhões de exemplares, adquiridos pelo Programa Nacional de Livro Didático (PNLD), cheguem simultaneamente no início do ano letivo em todos os recantos do território brasileiro ${ }^{4}$.

$\mathrm{Na}$ sociedade atual, capitalista, todo esse processo desemboca num produto, que é a mercadoria. Não se pode abstrair do livro - e do livro didático - a determinação de que ele é, antes de tudo, produzido para o mercado. Em todo caso, convém evitar o esquematismo simplista que vê em toda mercadoria

4 Esse, por sinal, era o principal ponto crítico do PNLD, que só foi resolvido com o contrato entre o Ministério da Educação e a Empresa de Correio e Telégrafos, em 1995 (ASSOCIAÇÃO..., 2004). 
a sombra do mal (e da indústria cultural). Afinal, um livro que conclama a derrubada do capitalismo é tão mercadoria quanto o que o exalta; o que conta é que um e outro vendam segundo uma estimativa. $\mathrm{O}$ importante é ter a exata noção de que a materialidade das relações que estão implicadas no livro, entre o autor e o leitor, é sobredeterminada pelo mercado ${ }^{5}$.

O livro didático, então, é uma mercadoria destinada a um mercado específico: a escola. Esta, como mostram Vincent, Lahire e Thin (2001), é uma instituição recente, que foi se consolidando a partir do século XVII, apresentando como traços principais:

a. "[...] espaço específico, separado das outras práticas sociais [...]" (ibidem, p. 28), para transmissão cultural de modo sistemático;

b. "[...] pedagogização das relações sociais de aprendizagem [...] ligadas à constituição de saberes escriturais formalizados, saberes objetivados, delimitados, codificados, concernentes tanto ao que é ensinado quanto à maneira de ensinar, tanto às práticas dos alunos quanto à prática dos mestres [...]" (ibidem, p. 28);

c. "sistematização do ensino", possibilitando "a produção de efeitos de socialização duráveis” (ibidem, p. 30);

d. "lugar de aprendizagem de formas de exercícios do poder" (ibidem, p. 30), que aparece como impessoal;

e. Instituição da "[...] forma social constitutiva do que se pode chamar uma relação escritural-escolar com a linguagem e com o mundo [...]" (ibidem, p. 35).

Em suma, a escola institui um espaço e uma temporalidade que não se reduz, como espelho ou reflexo, à sociedade que a contém, mas inaugura práticas e cultura que lhe são específicas. O livro didático, portanto, deve se adequar a esse mercado específico. Isso significa que a escola, tomada como mercado, determina usos específicos do livro (didático), também mediados pela sua materialidade. O termo “uso", empregado por Lajolo (1996), não é por acaso: o que na escola se faz com o livro didático não cabe na simples palavra "leitura". Certamente é para ser lido, mas essa leitura pode ser

5 Em O que é a história dos livros?, Darnton (1990, p. 113) apresenta um esquema que sumaria todo esse circuito pelo qual passa o livro até chegar às mãos do consumidor final, o leitor. Por motivos de direitos autorais (por sinal, um dos elementos que constituem esse circuito de livros), abstém-se de reproduzi-lo aqui. 
silenciosa ou em voz alta, individual ou coletiva; o seu texto pode ser copiado na lousa ou no caderno; suas páginas podem ser rabiscadas, os exercícios e pesquisas que sugere são realizados (às vezes, à revelia do próprio professor); é transportado da casa à escola, da escola para casa; etc. - cada atividade implicando práticas escolares diversificadas.

Diversas são também as funções que o livro didático assume na escola, como analisa Choppin (2004):

a. Referencial, contendo o programa da disciplina ou uma interpretação dele;

b. Instrumental, apresentando a metodologia de ensino, exercícios e atividades pertinentes àquela disciplina;

c. Ideológica e cultural, vetor "da língua, da cultura e dos valores das classes dirigentes" (ibidem, p. 553);

d. Documental, contendo documentos textuais e icônicos, "cuja observação ou confrontação podem vir a desenvolver o espírito crítico do aluno" (ibidem, p. 553).

Cada uma dessas funções pode ser tomada como um objeto de pesquisa. Além disso, devem-se incluir, como temas de pesquisa, aqueles que se referem a cada momento do ciclo da produção, circulação, distribuição e consumo do livro didático, sempre levando em conta as especificidades que marcam essa mercadoria. Apresentam-se a seguir alguns desses temas, tomando como exemplos teses, dissertações e relatórios de pesquisa de iniciação científica produzidos recentemente no âmbito do projeto de pesquisa "História das disciplinas escolares e do livro didático”, desenvolvido desde 2002 no Programa de Estudos Pós-Graduados em Educação: História, Política, Sociedade, da Faculdade de Educação, da Pontifícia Universidade Católica de São Paulo.

Um conjunto de temas refere-se à esfera da produção do livro didático. À primeira vista, essa questão é meramente técnica e só interessa a quem estiver envolvido em procedimentos de edição e editoração. Takeuchi (2005), no entanto, mostra, analisando a produção de uma editora de livros para a Educação de Jovens e Adultos (EJA), que estes não passam de versões reduzidas de seus congêneres para o ensino regular. Indica, assim, apenas examinando os aspectos editoriais (diagramação, tamanho dos textos, utilização das ilustrações), o descaso com que os livros da EJA são produzidos, sintoma também da precariedade dessa modalidade de ensino. Caberia verificar se 
a incorporação dos livros de EJA ao Programa Nacional do Livro Didático (resolução n. 51, de 16/9/2009) propiciou alteração dessa situação.

A análise da produção do livro didático também traz à tona a diversidade dos sujeitos que dela participam: autores, editores de texto, editores de arte, redatores, preparadores de texto e revisores, leitores críticos, consultores, pessoal de publicidade e marketing, divulgadores etc. Másculo (2008) analisa a produção de uma única coleção - a chamada "Coleção Sérgio Buarque de Hollanda" -, da Companhia Editora Nacional, mostrando a emergência de um autor coletivo, ainda que reunido em torno no nome (quase uma marca) do célebre historiador. Além disso, o autor ressalta o trabalho da editoria de arte, que torna viável a proposta pedagógica de utilizar as ilustrações não meramente como ornamento, mas como conteúdo efetivo. Para possibilitar a versatilidade na disposição das ilustrações (que deviam estar "amarradas" ao texto), o tamanho da página sofreu ampliação, assumindo o formato que se pratica até hoje. Também se revelam as estratégias editoriais para driblar a censura da ditadura militar e a imposição de estudos sociais em substituição às disciplinas história e geografia: como o titular da coleção se recusasse a escrever livros dessa nova disciplina, a editora manteve o mesmo texto de história, estampando na capa a expressão "Estudos Sociais"...

Alcanfor (2010) estuda as produções didáticas de Monteiro Lobato, ele mesmo editor. Trata-se de livros como História do mundo (1933), Emília no país da gramática (1934), Geografia de Dona Benta (1935) e Aritmética da Emília (1935), com que o autor pretende constituir modelo de literatura didática, contraposto aos livros correntes, que considera enfadonhos. Como se sabe, esse padrão, que buscou fazer da narrativa ficcional o suporte para os conteúdos didáticos, não teria continuidade, consolidando a distinção entre o livro didático e a literatura infantil e juvenil.

Ainda em relação às editoras, Braghini (2010) examina em sua tese, premiada pela Coordenação de Aperfeiçoamento de Pessoal de Nível Superior (CAPES), não exatamente os livros didáticos, mas uma revista que uma editora de livros didáticos produzia como prestação de serviço aos clientes e, claro, como propaganda de suas publicações. Mostra, assim, aspectos do pensamento dessa editora (e seus porta-vozes), por sinal, extremamente conservador, em relação à educação, aos estudantes e à juventude - o que também é revelador da política editorial assumida.

Uma das especificidades do livro didático é que essa mercadoria não se coloca simplesmente no mercado à espera do seu consumidor, mas a sua 
produção e sua distribuição são, em muitos países, reguladas pela mediação do Estado, havendo casos em que este assume a própria função de produzir o livro único. Choppin (1992) e Johnsen (1996) descreveram a relação entre o Estado e o mercado de livro didático em vários países; Apple (1995) discutiu a situação peculiar dos Estados Unidos em relação a essa questão. No Brasil, o Programa Nacional do Livro Didático, instituído em 1985, faz a mediação entre as editoras e o público-alvo (docentes e discentes das escolas públicas) e, a partir de 1996, quando se instituiu o sistema de avaliação prévia dos livros, intervém diretamente na oferta de livros, estabelecendo-lhes os critérios pelos quais possam ser apresentados à escolha dos professores (MUNAKATA, 1997).

Cassiano (2007), numa tese também premiada pela CAPES, revela o emaranhado de interesses políticos, educacionais e comerciais que constituem o mercado de livros didáticos e a política educacional no Brasil. Examina minuciosamente o Programa Nacional do Livro Didático e mostra como essa política pública, que faria do Estado brasileiro o maior comprador de livros didáticos do mundo, reconfigurou o mercado editorial no Brasil, atraindo grupos internacionais, em particular de origem espanhola. A autora mostra como o governo espanhol produziu diagnósticos dos mercados potenciais no mundo, induzindo e favorecendo maciço investimento de grupos espanhóis em países da América Latina, inclusive no Brasil. Num trabalho anterior, Cassiano (2003) descreveu a atuação dos divulgadores das editoras nesse mercado.

A avaliação dos livros didáticos pelos organismos do Estado constitui uma faceta da política pública desse material escolar e é objeto de análise de Filgueiras (2011), que examinou as práticas avaliativas anteriores ao PNLD. A sua intenção era também examinar as avaliações do PNLD, mas o acesso à documentação foi-lhe dificultado - na prática, negado pelos órgãos governamentais responsáveis pelo programa. Analisando detidamente as ações da Comissão Nacional do Livro Didático (CNLD), instituída em 1938, em plena ditadura do Estado Novo, constatou que, ao contrário do que se imagina, não houve censura de caráter político-ideológico, mas também não se apresentaram para avaliação livros passíveis de condenação.

Outro aspecto da política pública de livro didático refere-se à legislação. Contra um veredicto de que a legislação sobre o livro didático só passa a existir depois de 1930 (FREITAG; MOTTA; COSTA, 1993), Bocchi (2005) sumaria as leis do Império (ou melhor, desde a transferência da Corte 
portuguesa para o Brasil, em 1808), que direta ou indiretamente dizem respeito ao livro didático, ou seja, desde as que mencionam explicitamente títulos de livros a serem adotados nas escolas, até as que regulam as condições de produção de livros, como os impostos sobre a importação de papel ou tinta ou a instituição da censura.

Na outra ponta da política do livro didático, encontra-se a escolha pelo professor. No sistema em vigor desde 1996 no Brasil, a escolha do professor está restrita ao repertório que compõe o Guia de livro didático, que publica o resultado da avaliação realizada pela comissão instituída pelo Ministério da Educação ${ }^{6}$. Como se processa a escolha? Quais os critérios utilizados pelos professores? Cassiano (2003) constata uma série de dificuldades para o professor: o Guia não é distribuído para todos os professores, que só chegam a manuseá-lo quando da escolha, para o que normalmente se destina apenas um único dia. De resto, há queixas de que os pareceres do Guia são muito abstratos, pois, segundo os relatos, é com o próprio livro na mão, folheando-o, que se pode sentir se ele "funciona" ou não na sala de aula. Bisognin (2010), ao tentar verificar in loco uma reunião dos professores para a escolha dos livros didáticos de letramento e alfabetização linguística, constatou a presença de representante de uma editora, embora a prática de divulgação de livros no recinto da escola seja proibida por lei. Nessa medida, a qualidade de ensino propiciado pelo bom material é apenas uma das variáveis no processo de escolha do livro didático.

Um grupo temático bastante profícuo é formado por trabalhos que utilizam os livros didáticos como fontes para a análise da história de disciplinas escolares, cuja pesquisa foi impulsionada pelo artigo programático de Chervel (1990). As disciplinas, segundo a tese bastante conhecida deste autor, mantêm autonomia em relação às chamadas "ciências de referência", não se constituindo, portanto, de meras vulgarizações e simplificações, ou seja, “transposições didáticas" do saber erudito, acadêmico. Elas não são apenas

6 Quando se iniciou a avaliação, os livros eram classificados em quatro categorias: recomendados com distinção; recomendados; recomendados com ressalvas e não recomendados. A alta incidência de escolha de livros não recomendados fez com que se abolisse essa categoria, que passou a engrossar o rol dos excluídos do Guia de livro didático. As constantes reclamações por parte de autores e editoras também acabaram por eliminar a classificação e, do Guia, passaram a constar apenas os livros aprovados (CASSIANO, 2007). 
um conjunto de conteúdos ao qual se aplica uma "pedagogia lubrificante" (CHERVEL, 1990, p. 181); para Chervel (1990), a própria disciplina constitui a sua metodologia. Além disso, uma disciplina escolar é indissociável das finalidades do ensino escolar, sem o que não teria razão de ser. Para cumprir essas finalidades, uma disciplina compõe-se, além dos conteúdos, dos exercícios e das provas. Cabe, então, examinar como se selecionam e se organizam os conteúdos em cada momento da configuração de uma disciplina; como tal configuração implica uma metodologia; que modalidades de exercícios são propostas; e o que visam a aferir as provas e as avaliações. O livro didático é uma fonte privilegiada dessas indagações, na medida em que contém, por extenso, os conteúdos de cada disciplina e, eventualmente, as atividades e os exercícios. Na impossibilidade de observação direta das situações de ensino de outrora, o livro didático pode conter elementos que mais se aproximam dos programas curriculares então efetivados.

Gasparello (2004), em sua tese de 2002, posteriormente publicada como livro, estuda os compêndios de história do Brasil utilizados no Colégio Pedro II, a célebre instituição modelar do ensino secundário no Império e durante um longo período da República. Analisar esses livros equivale a examinar o modo como se foi constituindo, durante o Império, a disciplina história do Brasil, cuja finalidade era a construção da identidade nacional. Tursi (2005), ao examinar os compêndios de história adotados no Liceu de Curitiba (posteriormente Colégio Estadual do Paraná), identifica os padrões de apropriação dessa história na província de Paraná.

Disciplina pouco estudada na perspectiva proposta por Chervel, a geografia é objeto de estudo de Gomes (2010). Percorrendo vários livros didáticos, de Aroldo de Azevedo, Celso Antunes e os autores da chamada "Geografia crítica", ele mostra as mudanças de paradigma da geografia escolar, desde os anos 1960 até os dias atuais, passando pela reforma promovida pela ditadura militar, com a promulgação da lei n. 5.692, de 1971, que fundiu a história e a geografia em estudos sociais. Esta mesma lei instituiu a disciplina educação moral e cívica, que é examinada por Filgueiras (2006), em sua dissertação de mestrado. A autora ressalta que tal disciplina não foi uma invenção exclusiva da ditadura militar, além de evidenciar uma série de conflitos na sua implantação, tanto nas esferas governamentais e militares, quanto no interior mesmo da disciplina. Segundo a sua análise, havia desentendimentos entre o Conselho Federal de Educação, órgão do Ministério da Educação, e a Comissão Nacional de Moral e Civismo, ligada aos militares, o que abria 
brechas para os autores estabelecerem, por conta própria, os conteúdos. Pode-se verificar, então, a passagem de livros com forte conteúdo baseado na doutrina de Segurança Nacional para os que discutem questões como meio ambiente e cuidados com a saúde. De modo semelhante, Leonardo (2010) mostra como as abordagens que os livros didáticos de história faziam sobre o regime militar, durante a sua vigência, não podem ser consideradas como homogêneas e monolíticas; ao contrário, se havia livros didáticos que serviam como vetores da ideologia da ditadura, havia outros francamente oposicionistas.

Este último trabalho insere-se no grupo de pesquisas que examinam um determinado conteúdo. Nessa linha, podem-se citar as monografias de Mendes (2006) e de Boim (2006). A primeira examina o modo como a América Latina é representada nos livros didáticos de história e geografia, mostrando que tal representação constitui um intrincado jogo de espelhos distorcidos, em que se intercambiam o lugar da alteridade e da identidade: ora a América Latina engloba o Brasil, ora aparece como o outro do Brasil - e isto tanto no plano textual como no iconográfico e cartográfico. O segundo trabalho busca a representação da cultura afro-brasileira nos livros didáticos de história, comparando os livros anteriores aos posteriores à lei 10.639, de 2003, que torna obrigatória a presença de história da África e cultura afrobrasileira nos manuais didáticos.

A pesquisa sobre livros didáticos não pode deixar de lado os materiais que aparecem como seus sucedâneos. Esse é o caso das apostilas dos chamados "sistemas de ensino" - pacotes didáticos -, incluindo materiais impressos e assessoria pedagógica, vendidos por empresas de ensino privado às escolas e mesmo às prefeituras. Santos (2009) examinou a utilização desses materiais por escolas, colhendo a opinião de professores e diretores. Já Boim (2010) investigou o material apostilado de história que o governo do estado de São Paulo introduziu mediante uma nova proposta curricular, elaborada em 2007 para entrar em vigor a partir de 2008. Na sua avaliação, esse material, extremamente precário tanto na organização dos conteúdos como nas metodologias de ensino que prescreve, acaba reduzindo a autonomia do professor. Em todo caso, ao contrário do que se poderia esperar, não é unânime a condenação a esse material, seja do "sistema de ensino", seja do governo paulista.

Por sinal, cada livro didático supõe certos atributos do professor. Isso é mais evidente quando se trata de manuais para formação do professor. 
Zucchi (2012) examina os livros utilizados nos anos 1940 e 1950 no curso de formação de quadros do Serviço Nacional de Aprendizagem Industrial (SENAI), para determinar as representações sobre o que se espera de professores e instrutores dessa instituição de ensino profissional. É como se esses manuais formulassem os quesitos para o professor-padrão e o instrutorpadrão formarem o operário-padrão.

Uma disciplina escolar, como se viu, não se resume a um conjunto de conteúdos, mas também a exercícios e atividades correlacionados. Esse foi o objeto de pesquisa de Faricelli (2005), que buscou averiguar a presença implícita de finalidades educacionais e metodologias de ensino nos exercícios propostos em livros didáticos de história. Do mesmo modo, Faria (2009) estuda os exercícios nos livros didáticos de história, classificando-os em tipologias, a fim de verificar as suas ocorrências em três momentos: as décadas de 1940, 1970 e 2000.

Todos esses temas e abordagens esbarram em uma questão crucial: afinal, como são efetivamente utilizados os livros didáticos na sala de aula por professores e alunos? Eles funcionam, realmente, como muletas de professores mal preparados, como pretendem certos críticos do livro didático? Estes, ao tomarem tal formulação, como pressuposto a priori, dispensam a análise dos livros didáticos realmente existentes ou das situações reais de sua utilização ${ }^{7}$. Mas o que ocorre, efetivamente? Uma metodologia de pesquisa deve ser desenvolvida para tal investigação.

Uma via possível é o exame atento dos relatórios dos estágios supervisionados de prática de ensino, como propuseram Damaceno-Reis (2006), sobre o uso do livro didático da língua portuguesa, e Prado (2004), sobre o ensino de história. Esses relatórios são uma fonte bastante capciosa. Sabe-se que muitos deles são fraudados, descrevendo situações completamente fictícias. Além disso, contêm, com frequência, descrições pouco precisas do tipo "o professor trabalhou o livro didático". O que, efetivamente, fez o professor? Há também casos em que, do livro didático, por ser demais óbvio seu uso, não é sequer mencionado o título. Em todo caso, a leitura de séries de relatórios produz no investigador uma perspicácia que lhe permite detectar, com certa precisão, o que é real e o que é contrafação. Quanto a informações imprecisas, não há o que fazer, a não ser cercar o problema com certos indícios. Seria desejável que o professor responsável pelos estágios

7 Crítica representativa dessa vertente encontra-se em Silva (1998). 
supervisionados orientasse os alunos a prestarem atenção no uso do livro didático e serem mais precisos ao descrever as práticas observadas.

O trabalho de Damaceno-Reis (2006) constatou que, segundo os relatórios, o uso do livro didático é uma constante. Apesar disso, há diferenças de ênfase no aproveitamento de tópicos abordados pelos livros. No caso de Prado (2004), o objetivo não foi exatamente examinar o uso do livro didático, mas o próprio ensino de história. Isso não impediu, no entanto, que se atentasse para a presença constante desse material escolar e os vários procedimentos no seu manejo, em conformidade, de modo geral, com as prescrições pedagógicas ministradas nos cursos de licenciatura, em épocas diferentes, a saber, as décadas de 1970 e 1980.

Houve época em que estudar livro didático era visto como desvio de comportamento. Hoje, como se viu, há uma proliferação de temas e abordagens possíveis para o seu estudo. Pesquisas recentes, como as apresentadas no VIII Encontro Nacional Perspectivas do Ensino de História, em 2012, abordam a recepção dos livros didáticos pelo aluno - esse sujeito da educação escolar quase sempre em elipse. O que aqui se buscou mostrar, mediante alguns exemplos, é a fertilidade da pesquisa sobre o livro didático, que abre possibilidades de elucidação de vários aspectos da educação escolar e de sua história.

\section{Referências}

Associação Brasileira de Editores de Livros Escolares - ABreliVros. Correios entregam livros didáticos. São Paulo: ABRELIVROS, 2004. Disponível em: $\quad<$ http://www.abrelivros.org.br/index.php?option=com content\&view $=$ article\&id=3075: correios-entregam-livros-didaticos\&catid=4:pnl d\&Itemid=12>. Acesso em: 19 ago. 2012.

Alcanfor, Lucilene Rezende. Produçãoe circulação das obras didáticas de Monteiro Lobato. 2010. Dissertação (Mestrado em História da Educação) - Faculdade de Educação, Pontifícia Universidade Católica de São Paulo, São Paulo, 2010.

Apple, Michael Whitman. Trabalho docente e textos: economia política das relações de classe e de gênero em educação. Porto Alegre: Artes Médicas, 1995.

Araújo, Emanuel. A construção do livro: Princípios da técnica de editoração. Rio de Janeiro: Nova Fronteira, 1986. 
Bisognin, Andrea Guida. O processo de escolha das coleções de letramento e alfabetização linguística do Programa Nacional do Livro Didático. 2010. Dissertação (Mestrado em História da Educação)-Faculdade de Educação, Pontifícia Universidade Católica de São Paulo, São Paulo, 2010.

Bittencourt, Circe Maria Fernandes. Livro didático e conhecimento histórico: Uma história do saber escolar. 1993. Tese (Doutorado em História Social) - Faculdade de Filosofia, Letras e Ciências Humanas, Universidade de São Paulo, São Paulo, 1993.

. Livro didático e saber escolar: 1810-1910. Belo Horizonte: Autêntica, 2008.

Bocchi, Luna Abrano. A legislação sobre livro didático no Brasil (1808-1889). São Paulo: Faculdade de Educação, Pontifícia Universidade Católica de São Paulo, 2005. Relatório de Pesquisa (Iniciação científica em educação).

BoIm, Thiago Figueira. Cultura afro-brasileira nos livros didáticos brasileiros de história no ensino fundamental. São Paulo: Faculdade de Educação, Pontifícia Universidade Católica de São Paulo, 2006. Relatório de Pesquisa (Iniciação científica em educação).

. O que e como ensinar: proposta curricular, materiais didáticos e prática de ensino nas escolas públicas estaduais em São Paulo (2008-2009). 2010. Dissertação (Mestrado em História da Educação) - Faculdade de Educação, Pontifícia Universidade Católica de São Paulo, São Paulo, 2010.

Braghini, Katya Mitsuko Zuquim. A "vanguarda brasileira": a juventude no discurso da Revista Editora do Brasil S/A (1961-1980). 2010. Tese (Doutorado em História da Educação) - Faculdade de Educação, Pontifícia Universidade Católica de São Paulo, São Paulo, 2010.

Cassiano, Célia Cristina de Figueiredo. A escolha do professor e a circulação de livros didáticos no estado de São Paulo. 2003. Dissertação (Mestrado em História da Educação) - Faculdade de Educação, Pontifícia Universidade Católica de São Paulo, São Paulo, 2003.

. O mercado do livro didático no Brasil: da criação do Programa Nacional do Livro Didático (PNLD) à entrada de capital internacional espanhol (19852007). 2007. Tese (Doutorado em História da Educação) - Faculdade de Educação, Pontifícia Universidade Católica de São Paulo, São Paulo, 2007.

Castro, Rui Vieira de et al. (Orgs.). Manuais escolares: estatuto, funções, história. Braga: Centro de Estudos em Educação e Psicologia da Universidade do Minho, 1999. 
Chartier, Roger. A história cultural: entre práticas e representações. Lisboa: DIFEL; Rio de Janeiro: Bertrand Brasil, 1990.

Chervel, André. História das disciplinas escolares: Reflexões sobre um campo de pesquisa. Teoria \& Educação, Porto Alegre, n. 2, p. 177-229, 1990.

Choppin, Alain. História dos livros e das edições didáticas: sobre o estado da arte. Educação e pesquisa, São Paulo, p. 549-566, set./dez. 2004.

. Les manuels scolaires: histoire et actualité. Paris: Hachette, 1992.

Damaceno-Reis, Angela Maria. O uso do livro didático de língua portuguesa por professores do ensino fundamental. 2006. Dissertação (Mestrado em História da Educação) - Faculdade de Educação, Pontifícia Universidade Católica de São Paulo, São Paulo, 2006.

DARNTON, Robert. O que é a história dos livros? In: . O beijo de Lamourette: mídia, cultura e revolução. São Paulo: Companhia das Letras, 1990. p. 109-172.

FARIA, Joana Borges de. Exercícios didáticos de história do Brasil: ensino fundamental de $5^{\mathrm{a}}$ a $8^{\mathrm{a}}$ séries. São Paulo: Faculdade de Educação, Pontifícia Universidade Católica de São Paulo, 2009. Relatório de Pesquisa (Iniciação científica em educação).

Faricelli, Marilu de Freitas. Conteúdo pedagógico da história como disciplina escolar: exercícios propostos por livros didáticos de $5^{\mathrm{a}}$ à $8^{\mathrm{a}}$ série. 2005. Dissertação (Mestrado em História da Educação) - Faculdade de Educação, Pontifícia Universidade Católica de São Paulo, São Paulo, 2005.

FilgueIras, Juliana Miranda. A educação moral e cívica e sua produção didática: 1969-1993. 2006. Dissertação (Mestrado em História da Educação) - Faculdade de Educação, Pontifícia Universidade Católica de São Paulo, São Paulo, 2006.

. Os processos de avaliação de livros didáticos no Brasil (1938-1984). 2011. Tese (Doutorado em História da Educação) - Faculdade de Educação, Pontifícia Universidade Católica de São Paulo, São Paulo, 2011.

Freitag, Bárbara; Motta, Valéria Rodrigues; Costa, Wanderly Ferreira da. O livro didático em questão. 2. ed. São Paulo: Cortez, 1993.

Gasparello, Arlete Medeiros. Construtores de identidades: a pedagogia da nação nos livros didáticos da escola secundária brasileira. São Paulo: Iglu, 2004. 
- Construtores de identidades: os compêndios de historia do Brasil do Colegio Pedro II (1838-1920). 2002. Tese (Doutorado em História da Educação) - Faculdade de Educação, Pontifícia Universidade Católica de São Paulo, São Paulo, 2002.

Gomes, Daniel Mendes. A geografia ensinada: mudanças e continuidades do conhecimento geográfico escolar (1960-1989). 2010. Dissertação (Mestrado em História da Educação) - Faculdade de Educação, Pontifícia Universidade Católica de São Paulo, São Paulo, 2010.

Goodson, Ivor. Historia del currículum: La construcción social de las disciplinas escolares. Barcelona: Pomares-Corredor, 1995.

Johnsen, Egil Børre. Libros de texto en el calidoscopio: Estudio crítico de la literatura y la investigación sobre los textos escolares. Barcelona: PomaresCorredor, 1996.

Lajolo, Marisa. Livro didático: um (quase) manual de usuário. Em Aberto, Brasília, v. 16 n. 69 , p. 3-9, jan./mar. 1996.

LeOnardo, Natalia Moura. Abordagens do regime militar brasileiro nos livros didáticos de ensino fundamental e ensino médio (1964-1989). São Paulo: Faculdade de Educação, Pontifícia Universidade Católica de São Paulo, São Paulo, 2010. Relatório de Pesquisa (Iniciação científica em educação).

Másculo, José Cássio. A coleção Sergio Buarque de Hollanda: livros didáticos e ensino de história. 2008. Tese (Doutorado em história da educação) - Faculdade de Educação, Pontifícia Universidade Católica de São Paulo, São Paulo, 2008.

Mendes, Sarayna Martins. América Latina nos livros didáticos de história e geografia. São Paulo: Faculdade de Educação, Pontifícia Universidade Católica de São Paulo, 2006. Relatório de Pesquisa (Iniciação científica em educação).

Munakata, Kazumi. Histórias que os livros didáticos contam, depois que acabou a ditadura no Brasil. In: Freitas, Marcos Cezar (Org.). Historiografia brasileira em perspectiva. São Paulo: Contexto, 1998. cap. 4, p. 271-296.

. Produzindo livros didáticos e paradidáticos. 1997. Tese (Doutorado em história e filosofia da educação) - Pontifícia Universidade Católica de São Paulo, São Paulo, 1997.

Prado, Eliane Mimesse. As práticas dos professores de história nas escolas estaduais paulistas nas décadas de 1970 e 1980. 2004. Tese (Doutorado em História da Educação) - Faculdade de Educação, Pontifícia Universidade Católica de São Paulo, São Paulo, 2004. 
Ribeiro, Milton. Planejamento visual gráfico. 8. ed. rev. e atual. Brasília: LGE, 2003.

Santos, Tainã Maria Pinheiro dos. Publicações dos sistemas de ensino no ensino fundamental: alternativa para o livro didático? São Paulo: Faculdade de Educação, Pontifícia Universidade Católica de São Paulo, 2009. Relatório de Pesquisa (Iniciação científica em educação).

Silva, Ezequiel Theodoro da. Criticidade e leitura: ensaios. Campinas: ALB, Mercado de Letras, 1998.

Simpósio Internacional “Livro Didático: Educação e História”, 2007, São Paulo. Programa e Caderno de Resumos... São Paulo: FEUSP, 2007.

TAKeuchi, Marcia Regina. Análise material de livros didáticos para educação de jovens e adultos. 2005. Dissertação (Mestrado em História da Educação) - Faculdade de Educação, Pontifícia Universidade Católica de São Paulo, São Paulo, 2005.

Tursi, Maria Aparecida Leopoldino. A disciplina de história no Paraná: os compêndios de história e a história ensinada (1876-1905). 2005. Tese (Doutorado em História da Educação) - Faculdade de Educação, Pontifícia Universidade Católica de São Paulo, São Paulo, 2005.

Vincent, Guy; Lahire, Bernard; Thin, Daniel. Sobre a história e a forma escolar. Educação em Revista, Belo Horizonte, n. 33, p. 7-47, jun. 2001.

ZuCCHI, Bianca Barbagallo. Curso de quadros: formação de professores e instrutores pelo/para o SENAI - São Paulo (1942-1955). 2012. Tese (Doutorado em História da Educação) - Faculdade de Educação, Pontifícia Universidade Católica de São Paulo, São Paulo, 2012.

Endereço para correspondência: Kazumi Munakata Rua Ministro Godói, 969, Bloco A, Sala 4E-19

Perdizes São Paulo - SP CEP: 05015-901 E-mail:kazumi@pucsp.br

Recebido em: 28 dez. 2011 Aprovado em: 23 ago. 2012 
